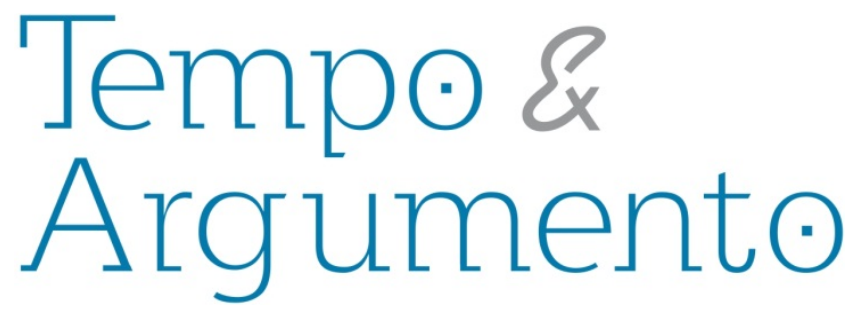

\title{
Representação do Passado e História Pública: a História das Mulheres na Internet
}

\section{Resumo}

Este artigo tem por objetivo abordar as relações entre internet, representação do passado e história pública. Para tanto, se valerá da análise do website e página do Facebook “As Mina na História”, criada em junho de 2015. Neste exame, explorará questões tais como o tipo de representação do passado oferecido neste espaço virtual, o perfil da sua audiência e a linguagem utilizada. A fim de avançar em tais problemáticas, são tecidos alguns breves comentários sobre o ensino de história das mulheres no Brasil. Por fim, busca-se, a partir desta abordagem, propor algumas reflexões sobre a história pública que tem sido praticada no país, para além da questão da ampliação do público "consumidor" de história.

\author{
Gabriela Correa da Silva \\ Doutoranda no Programa de Pós-Graduação \\ em História da Universidade Federal do Rio \\ Grande do Sul. Bolsista CNPq. \\ Brasil \\ gabicorrea.s@hotmail.com
}

Palavras-chave: Representação; História Pública; Internet; Mulheres.

\section{Para citar este artigo:}

CORREA DA SILVA, Gabriela. Representação do Passado e História Pública: a História das Mulheres na Internet. Revista Tempo e Argumento, Florianópolis, v. 8, n. 19, p. 162 - 184. set./dez. 2016. 


\title{
Representation of the Past and Public History: the History of Women on the Internet
}

\begin{abstract}
This article approaches the relationship between the Internet, the representation of the past, and Public History. For this purpose, the website and Facebook page named "As Mina na História", created in June 2015, is analyzed. This examination explores issues such as the type of representation of the past offered in this virtual space, profile of its audience and the language used by the page administrators. In order to move forward in these issues, brief comments about the teaching of women's history in Brazil are made. Finally, we seek through this approach to offer some considerations about the Public History that has been practiced in Brazil, beyond the issue of expansion of the "consumer" of history.
\end{abstract}

Keywords: Representation; Public History; Internet; Women.

\section{Considerações iniciais}

O debate sobre o que é história pública é bastante amplo e tem variações conforme o contexto nacional. Tendo surgido nos Estados Unidos, nos anos 1970, em decorrência, principalmente, do alto número de acadêmicos desempregados, passou, desde então, a ser praticada em diversos países, com diferentes ênfases e concepções (LIDDINGTON, 2011). Este texto parte do entendimento de que a história pública consiste na produção de conhecimento histórico, realizada não exclusivamente por um (a) historiador (a) profissional, com ampla circulação na sociedade (FERREIRA, 2011). $\mathrm{Na}$ segunda metade deste artigo, serão tecidas maiores considerações e proposições acerca desta definição. 
Há, nos textos dedicados à reflexão sobre esta temática, certo consenso a respeito do fato de que, atualmente, há uma explosão de demanda pública por história no Brasil. A constatação é feita por um número crescente de autores. Para Jurandir Malerba (2014), por exemplo, a existência e o sucesso de diversas revistas de divulgação científica, programas de televisão (novelas e minisséries), websites e páginas nas redes sociais que têm o passado como temática podem ser vistos como sintomas do fenômeno.

$\mathrm{Na}$ esteira deste movimento, é possível observar a crescente popularidade da representação do passado das mulheres ${ }^{1}$, o que tem aberto espaço para websites e perfis nas redes sociais que buscam dar visibilidade à história e memória feminina. Este é o caso do website e também perfil do Facebook que este artigo visa analisar, cujo nome é "As Mina na História"².

Idealizada por uma estudante do Ensino Médio da rede pública do Rio de Janeiro em junho de 2015, a página conta, atualmente, com aproximadamente 315 mil curtidas no Facebook $^{3}$. De acordo com entrevista ${ }^{4}$ concedida pela criadora da página, Sigrid Beatriz

Cito, como exemplo de publicações destinadas à divulgação do conhecimento histórico que têm aproveitado este momento, sendo, ao mesmo tempo, causa e sintoma dele, o excelente dossiê da Revista de História da Biblioteca Nacional "Feminismos: modos de pensar, modos de fazer", ano 10, n 113, de fevereiro de 2015. A propósito da temática, também cabe aqui uma observação: embora trate da representação do passado das mulheres, este texto não analisará a história das mulheres ou do feminismo no Brasil. Sobre estas temáticas, ver o interessante livro organizado por Carla B. Pinsky e Joana Maria Pedro, intitulado "Nova História das Mulheres no Brasil”, publicado em 2012 pela Editora Contexto.

2 Gostaria de registrar aqui meu agradecimento àquelas e àqueles que contribuíram para o desenvolvimento das reflexões propostas neste artigo. Para tanto, foram enriquecedoras as discussões proporcionadas pelo GT de teoria da história e historiografia/Anpuh-RS, coordenado pela professora Renata Dal Sasso (UNIPAMPA) e por Juliano Antoniolli (UFRGS), bem como os debates do Simpósio Temático "História Pública, Tecnologia e Representação do passado", coordenado por Pedro Telles da Silveira e luri Bauler, no $9^{\circ}$ Seminário Brasileiro de História da Historiografia, sediado em Vitória/ES. Este texto começou a ser escrito para ser apresentado no referido Simpósio. Em especial, gostaria de agradecer ao Juliano, pela leitura sempre atenta, e ao Pedro pelas sugestões de leitura e pelos comentários, sobretudo no que se refere às possíveis tramas entre história e infâmia.

3 Para efeito de comparação, cito o perfil do Facebook do "Café História", por exemplo, criado pelo jornalista e historiador Bruno Leal, que conta, atualmente, com cerca de 470 mil curtidas. Outro exemplo é a página do historiador Leandro Karnal, que tem tido significativa popularidade nas redes sociais, com também 470 mil curtidas. Ambos os perfis podem ser visitados nestes links: <https://www.facebook.com/prof.leandrokarnal/?fref=ts>

<https://www.facebook.com/CafeHistoria/?fref=ts>. Acesso em 15/05/2016. O perfil "As Mina na História" pode ser acessado neste link: <https://www.facebook.com/asminasnahistoria/?fref=ts> e o site em: <http://asminanahistoria.com.br/category/geral/>. Acesso em 10/08/2016.

4 A entrevista, publicada em 19/02/2016, está disponível no portal Mídia Max: <http://www.midiamax.com.br/midiamais/criado-campo-grandense-projeto-mostra-quem-sao-minasfizeram-historia-290580>. Acesso em 15/05/2016. 
Varanis Ortega, ao portal de notícias Mídia Max, a ideia de criação do site e do perfil no Facebook surgiu a partir de sua participação na sétima Olimpíada Nacional de História, em 2015, como aluna do Centro Integrado de Educação Pública (CIEP) Brizolão 362 Roberto Burle Marx.

Então com 17 anos, Sigrid deparou-se, ao longo da sua participação na Olimpíada, com uma foto da primeira mulher cangaceira na história do Brasil, Maria Gomes de Oliveira - Maria Bonita -, que não conhecia. A partir deste momento passou a questionar o quão pouco havia aprendido sobre a história das mulheres no ensino que recebeu na escola. Esta experiência a motivou a criar o projeto “As Mina na História”, cujo objetivo é: "resgatar a memória e o trabalho de mulheres que transformaram o mundo, e ainda assim acabaram apagadas da História." (“As Mina na História”, Facebook, 2015). Em entrevista ao Jornal Correio do Estado ${ }^{6}$, Sigrid afirma ser este resgate importante para que as mulheres se inspirem e se sintam representadas e encorajadas, já que, em seu diagnóstico, os feitos femininos foram apagados ou ignorados.

Esta iniciativa é bastante instigante para nós, historiadoras e historiadores de ofício. Entre tantas questões suscitadas, podemos formular aqui algumas: que tipo de representação do passado é oferecido neste espaço virtual? Qual passado é demandado pelas (os) seguidoras (es) do perfil? Qual é a audiência do projeto “As Mina na História”? Qual é a linguagem utilizada?

A análise deste caso específico busca ampliar a discussão em torno do que é história pública e como ela vem sendo praticada no Brasil. Para tanto, na primeira e segunda seções deste texto serão exploradas as duas primeiras questões acima

5 Esta citação nos faz pensar no problema das relações entre história e memória, que não será aprofundado neste texto. É necessário, contudo, um breve comentário a respeito. Busca-se, aqui, sugerir que "As Mina na História” pode ser entendido como uma modalidade de História Pública, pelas razões que serão adiante indicadas, e não somente de exercício online de reforço/construção da memória e identidade de um grupo. Não há, entretanto, uma divisão rígida entre história e memória e não se pretende defender isso. Como é sabido, para Paul Ricoeur (2007), a memória é a matriz da história, no sentido de que tudo começa no testemunho daquele que lembra e de que ambas compartilham tal testemunho. Não há, então, um divórcio entre elas. Tendo clareza desta relação, não se avançará nesta análise no caso específico aqui enfocado por uma questão de espaço e recorte temático.

6 A entrevista, publicada em 08/03/2016, está disponível no portal do jornal Correio do Estado: <http://www.correiodoestado.com.br/arte-e-cultura/juventude-feminina-se-insere-cada-vez-mais-nabusca-por-igualdade-de/272551/>. Último acesso em 22/11/2016. 


\section{As mulheres têm história?}

A maior parte da história das mulheres tem buscado de alguma forma incluir as mulheres como objetos de estudo, sujeitos da história.

(SCOTT, 2011, p. 79)

No texto "História das mulheres", publicado orginalmente no início dos anos 1990, Joan Scott (2011), professora no Instituto de Estudos Avançados, em Princeton, menciona o longo período de obliteração da presença feminina na história. Neste estudo, a autora recorre aos escritos de Virgínia Woolf, no conhecido livro que reúne algumas das suas conferências pronunciadas na década de 1920, intitulado "Um Teto todo Seu”. Woolf, ao fazer uma comparação entre a presença das mulheres na ficção e sua ausência na história, questiona a falta de pesquisas, em fins da década de 1920, que abordassem a vidas das mulheres:

Todos esses fatos estão em algum lugar, presumivelmente nos registros e livros contábeis paroquiais; a vida da mulher média elisabetana deve estar espalhada em algum lugar, disponível para alguém que se preste a recolhê-la e dela fazer um livro. Uma ambição que ultrapassaria minha audácia, pensei, procurando pelas prateleiras os livros que não estavam ali, seria sugerir às alunas dessas famosas universidades que reescrevessem a história, embora deva admitir que, muitas vezes, ela parece um tanto estranha tal como é - irreal, tendenciosa; - mas por que não poderiam elas acrescentar um suplemento à história, dando-lhe, é claro, algum nome não conspícuo, de modo que as mulheres pudessem ali figurar sem impropriedade? Pois frequentemente as percebemos de relance na vida dos grandes homens, despachadas logo para o segundo plano, ocultando, às vezes, um piscar de olhos, um riso, uma lágrima talvez. (WOOLF, 1987, p. 57-58)

Não é sem razão que a frase de abertura da página “As Mina na História”, mencionada com a devida indicação de referência, pertence ao livro de Woolf ora citado: 

alguma alteração na escrita da história das mulheres?

Segundo Scott, o estudo da história das mulheres já não é novidade na historiografia profissional. Ao expor o estado da arte na área naquele momento, a autora o considerava como um campo definível já desde as duas últimas décadas, ou seja, desde fins dos anos 1960. Apesar disso, parece existir, como em muitas temáticas pesquisadas academicamente, um descompasso entre produção e circulação do conhecimento. Entre a academia e a escola, para nos determos em um dos tantos exemplos possíveis, há um longo trajeto. O caso brasileiro serve de ilustração do problema.

O artigo "O ensino de história e os estudos de gênero na historiografia brasileira", de autoria de Ana Maria Colling e Losandro Tedeschi (2015), aborda, entre outras questões, diversos silenciamentos no ensino de história. Os autores, partindo do conceito de gênero, enquanto diferença de sexos baseada na cultura e produzida pela história, apontam a escola e o ensino da história como sendo, historicamente, lugares de demarcação sexual de ocultação das diferenças. Dessa forma, argumentam que abordar as relações de gênero no ensino da historia é uma tarefa urgente.

A escola, contudo, enquanto primeiro espaço onde se pratica o currículo, está intimamente ligada e submersa na cultura patriarcal. Daí algumas das dificuldades de se abordar e enfrentar a questão da história das mulheres, bem como de outros grupos historicamente excluídos, neste espaço. Assim, os autores questionam: qual livro de história, comumente usado em salas de aula no Brasil, aborda as histórias femininas?

Acompanhando o relato das histórias ocidentais, a história do Brasil foi feita somente pelos homens. A invisibilidade da mulher na construção da sociedade brasileira é um fato detectado em qualquer manual que tenta contar nossa história relativa aos primeiros tempos. Por uma questão biológica, sem contar outras, ninguém pode negar a existência do sexo feminino, responsável pela reprodução de homens e mulheres. Mas por onde andava ele, afinal? A história do Brasil, como a dos povos ocidentais, é uma história masculina na qual não sobrou espaço para as mulheres. (COLLING; TEDESCHI, 2015, p. 300) 
Seria adequado, portanto, indagar constantemente quais conhecimentos e grupos sociais são incluídos e excluídos do relato histórico. ${ }^{7}$ Que divisões do sujeito - gênero, raça, classe são produzidas ou reforçadas pela historiografia, expressas principalmente nos livros didáticos de História? Retomando algumas das reflexões centrais de Michel Foucault em vários momentos de sua produção, Ana Maria Colling e Losandro Tedeschi concluem seu texto de forma provocativa:

Acostumamos a encarar a história como algo ligado ao cognitivo, às informações, aos fatos, desprovidos de relações de poder e saber. Deixamos de vê-la em seus aspectos de disciplinamento, de silêncios. Analisar quem a história convoca ou silencia nos seus textos discursivos deveria ser uma tarefa permanente do historiador. (COLLING; TEDESCHI, 2015, p. 310)

Buscando avançar na compreensão do caso aqui analisado, caberia o questionamento: quando os mencionados silenciamentos são percebidos e geram desconforto nas (os) alunas (os), o que pode acontecer com a história ensinada e divulgada, seja na escola ou em outros ambientes? Parece-nos que, em situações como esta, as representações consagradas passam a ser desafiadas das mais diversas formas, nos mais variados espaços, por múltiplos sujeitos ${ }^{8}$. Com o uso cada vez mais intenso da internet, estas contestações ganham grande visibilidade. Pode ser este o caso na iniciativa “As Mina na História”.

Apesar da tendência histórica descrita pelos autores acima citados, é importante destacar que, recentemente, a história das mulheres vem sendo incorporada aos livros didáticos que são utilizados em todo o país. É possível observar esta progressiva mudança ao analisarmos o guia de livros didáticos PNLD 2015/Ensino Médio - publicado pela Secretaria de Educação Básica, vinculada ao Ministério da Educação. Este guia faz um apanhado das obras disponibilizadas pelo MEC. Nas resenhas das 18 coleções oferecidas para a escolha das professoras e professores da rede pública, é possível notar a preocupação com a temática da história das mulheres em mais da metade dos livros. A forma como se dá esta presença, contudo, ainda parece tímida. De acordo com as resenhas, muitos livros abordam a temática em boxes separados do texto principal. Agradeço à Carmem Gil (UFRGS) pela leitura atenta deste artigo e pela sugestão de análise do PNLD.

8 O caso discutido neste artigo é um entre tantos. Há, inclusive, inúmeras páginas na internet e perfis no Facebook que buscam vocalizar representações do passado bastante reacionárias. Nesse sentido, este artigo busca convidar, historiadores e historiadoras, a pensar esta nova realidade que ganha espaço com o avanço da tecnologia e nosso papel nestes novos ambientes. 
Ao explicar o despertar do seu interesse pela história das mulheres, a idealizadora da página é crítica quanto ao ensino de história que recebeu na escola9: "Eu me interessei e pesquisei sobre ela [Maria Bonita]. Essa busca trouxe a reflexão de que, em toda a minha vida escolar, pouquíssimas vezes tinha aprendido sobre as mulheres e seus feitos."10

Nesse sentido, é flagrante a relação desta percepção com a dos norte-americanos entrevistados por Roy Rosenzweig e David Thelen (1998). Perguntados sobre suas relações com as representações do passado, muitos entrevistados afirmaram que, quando estudaram história na escola, não se sentiam conectados às grandes narrativas e não viam, em função disso, sentido em estudar história. De modo geral, no entanto, eles demonstraram ter grande interesse pelo estudo do passado, mas de forma que pudessem utilizá-lo em seu cotidiano, de acordo com suas necessidades.

Esta parece ser uma das questões que desperta interesse do público pelo projeto “As Mina na História”. Nas postagens, há uma busca por conectar a história das mulheres às narrativas sobre a história do Brasil, por exemplo. O caso do texto publicado no site em 25 de abril de 2016 é revelador. Intitulada "3 mulheres excluídas de sua aula de história do Brasil""11, a postagem, com 813 palavras (4.147 caracteres) e três imagens, aborda a presença de três perfis femininos, que participaram na luta contra os revoltosos que não aceitaram a Independência. $O$ texto começa assim:

Dom Pedro I proclamou a Independência no dia 7 de setembro de 1822. Mas nem todo mundo aceitou o fato. Muitos portugueses radicados se indignavam, especialmente no Maranhão e na Bahia. Do litoral ao interior baiano, houve muita revolta. Essas três mulheres baianas são símbolos da resistência, mas quase nunca estão nos livros didáticos das escolas. ("As Minas na História", website, 2016)

9 Sabemos que a realidade nacional é muito diversa e que podem existir variações de acordo com a região, a rede (pública ou privada, com a balança não necessariamente pendendo para a segunda) ou mesmo nas diferentes escolas dentro de uma mesma rede. Com esta citação, não se busca aqui analisar a situação do ensino de história das mulheres no país como um todo. O importante é avançarmos na percepção da criadora da página que, no fim das contas, foi o que a mobilizou para dar início ao projeto ora estudado.

10 A entrevista, publicada em 08/03/2016, está disponível no portal do jornal Correio do Estado: <http://www.correiodoestado.com.br/arte-e-cultura/juventude-feminina-se-insere-cada-vez-mais-nabusca-por-igualdade-de/272551/>. Último acesso em 22/11/2016.

11 Texto disponível em: <http://asminanahistoria.com.br/3-mulheres-excluidas-da-sua-aula-de-historia>. Acesso em 16/05/2016. 
Em seguida, conhecemos a história de Maria Felipa de Oliveira, negra e pobre, quase nunca lembrada por seus feitos, nascida escrava, tornou-se liberta e aprendeu a lutar capoeira para se defender. Ao longo do texto, há a informação de que ela lutou contra os portugueses, na Bahia, quando da revolta destes com a declaração de Independência do Brasil. Após vencer a luta da qual participava com função decisiva, Maria Felipa continuou levando sua vida de capoeirista e marisqueira, sendo admirada pelo povo. Ela faleceu em 04 de janeiro de 1873.

Joana Angélica, por sua vez, foi abadessa no Convento de Nossa Senhora da Conceição da Lapa, em Salvador. Era diretora do convento quando, em fevereiro de 1822, foi atacada por soldados das tropas portuguesas. Ao resistir à invasão do Convento, ela recebeu golpes de baioneta e faleceu no dia seguinte: “Na época, seu assassinato serviu como um dos estopins para o início da revolta dos brasileiros. Joana tornou-se a primeira mártir da grande luta que continuou até 2 de julho" (“As Minas na História”, website, 2016).

Por fim, conhecemos a breve biografia de Maria Quitéria, que fugiu de casa para lutar, passando-se por homem. Após ser descoberta pelo pai, foi defendida pelo comandante do batalhão, pois mostrava grande habilidade com armas. Dessa forma,

em 2 de julho de 1823, quando o "Exército Libertador" entrou em triunfo na cidade do Salvador, Maria Quitéria foi saudada e homenageada pela população em festa. Maria foi a primeira mulher a assentar praça numa unidade militar das Forças Armadas Brasileiras e a primeira mulher a entrar em combate pelo Brasil. Em 28 de julho de 1996, foi reconhecida como Patronesse do Quadro Complementar de Oficiais do Exército Brasileiro. Por determinação ministerial, sua imagem deve estar em todos os quartéis do país. (“As Minas na História”, website, 2016)

O que há em comum na apresentação das três personagens? Inicialmente, e isto é evidente, podemos destacar que a narrativa busca afirmar a existência de mulheres que lutaram. Elas tomaram parte nos episódios considerados nevrálgicos na história do Brasil, embora não costumem ser lembradas. Há uma forte marca e destaque para o heroísmo destas ações. A narrativa deste passado parece ter dois sentidos fundamentais: 1) através dos exemplos trazidos, estimular a continuidade da luta; 2) dar visibilidade a esta presença, não permitindo que ela continue sendo esquecida. 
É possível, portanto, afirmar que o tipo de representação do passado oferecido no site e no perfil do Facebook de "As Mina na História” é um convite à desnaturalização da invisibilidade da história das mulheres diagnosticada pela criadora do projeto. 0 diagnóstico, por sua vez, parece ter repercutido nas (nos) seguidoras (es) da página. Não são raros os comentários, seja no site ou no Facebook, no sentido de parabenizar as postagens por recuperar a história das mulheres. Um exemplo é o comentário de uma usuária, em postagem de 16/05/16: “Gente, essa página é tão maravilhosa! A cada postagem sinto mais orgulho de nossa história, mais vontade de fazer a diferença" ("As Mina na História", Facebook, 2016).

Desse modo, o projeto aqui analisado parece ser uma forma de dar voz a alguns dos sujeitos subalternos (as) da história: seja criando um espaço para isso ou, ainda, ocupando um lugar de fala ${ }^{12}$. Nesse sentido, são relevantes as considerações de Gayatri Spivak (2010). A pensadora vincula-se ao conjunto de autores que se intitulam póscoloniais. Tais pesquisadores explicitam a necessidade de pensar a escrita da história para além dos modelos oferecidos pelos colonizadores e associados ao mundo ocidental. A intelectual indiana, por sua vez, enfatiza um problema central: o de contestar a inquestionável mudez da mulher subalterna. Nas palavras da autora: "Se, no contexto da produção colonial, o sujeito subalterno não tem história e não pode falar, o sujeito subalterno feminino está ainda mais profundamente na obscuridade" (SPIVAK, 2010, p. 67). Assim, Spivak se une aos esforços para dar à (ao) subalterna (o) uma voz na história.

\footnotetext{
12 A propósito, o estudo de Bonnie Smith (2003) intitulado "Gênero e História: homens, mulheres e a prática histórica" é interessante para ampliar a compreensão do projeto "As Mina na História". O argumento é que, mesmo não sendo o projeto aqui enfocado conduzido por historiadoras (es) profissionais, a iniciativa traz muitos elementos importantes para pensarmos a escrita e a prática da história pública no Brasil hoje. É neste sentido que a reflexão de Smith nos é valiosa: ao estudar as historiadoras amadoras de fins do século XVIII e início do século XIX, a pesquisadora ressalta a conformação da história enquanto campo baseado na distinção de gênero. As amadoras produziam para um público amplo, enquanto os seminários eram espaços predominantemente masculinos, "científicos" e circunscritos aos "iniciados". Nas palavras da autora: "Entretanto, uma leitura mais sintomática do amadorismo revela que a história amadora consiste em algo verdadeiramente extraordinário: o relato de múltiplos traumas e não apenas dos relacionados a guerras e revoluções. Quando se examina o amadorismo sob essas linhas, é possível compreender melhor como essa moderna historiografia do mundo ocidental esteve marcada pelo gênero" (SMITH, 2003, p. 90). Agradeço à professora Mara Rodrigues (UFRGS) pela sugestão bibliográfica e pela interlocução constante.
} 
Considerando o exposto até aqui, é possível afirmar que a iniciativa ora abordada colabora para atribuir crédito às mulheres na história, contribuindo para recolocá-las no tempo. Seria pertinente, então, encará-la como uma forma de fazer a "História das Mulheres Infames", para mencionarmos algo próximo do projeto de Michel Foucault? Ou ainda uma manifestação da crítica de Jorge Luis Borges à história universal, à moda da “História Universal da Infâmia”?

\section{História e Infâmia}

É sabido que, entre as tantas contribuições de Michel Foucault para a reflexão sobre a história, podemos citar seu contundente alerta para a produção de silêncios na narrativa historiográfica. Este é o caso do texto de sua autoria intitulado "A Vida dos Homens Infames". Publicado originalmente nos anos 1970, com estes escritos, Foucault, mais uma vez, chama a atenção dos leitores para as vidas singulares, obscuras e desventuradas: vidas que são como se não tivessem sido.

Ao explicar suas ideias, o autor diferencia estes infames daqueles indivíduos cuja conduta, permeada por delitos, gera assombro ou escândalo. Estes seriam tipos da lenda gloriosa. Esta infâmia, da conduta odiosa, não é senão uma modalidade universal da fama. Assim, são infames, no sentido estrito, os personagens escolhidos por Foucault (2003): eles não têm nenhum tipo de glória, nem mesmo a vil; eles não têm fama. Suas trajetórias só podem ser conhecidas a partir do seu cruzamento com o poder, cujo objetivo não era outro senão aniquilá-las ${ }^{13}$.

13 As fontes utilizadas por Michel Foucault datam do período entre 1660 e 1760 e provêm de arquivos do internamento, da polícia, das petições ao rei e das cartas régias com ordem de prisão-internamento (lettres de cachet). Em um dos documentos utilizados, por exemplo, alegava-se que Mathurin Milan, habitante da França do século XVIII, sofria de loucura porque levava uma vida afastada dos familiares e emprestava dinheiro de forma imprudente. Em função disso, devia ser afastado do convívio social. A propósito da nota, agradeço ao professor Temístocles Cezar pela indicação desta leitura de Foucault. Registro aqui que ele já fez, antes de mim, a associação de Borges e Foucault em contexto de menção à questão da infâmia. O texto ao qual faço referência intitula-se "Bartleby e Nulisseu: a arte de contar histórias de vida sem biografia" e foi debatido no GT de teoria da história e historiografia/Anpuh-RS. Escrito para ser um capítulo de livro, este texto tem uma versão disponível na página do GT, no Academia.edu. 
Dessa forma, Foucault se debruça sobre homens e mulheres que, nas suas palavras, não foram nada na história, que não desempenharam nos acontecimentos ou entre as pessoas importantes nenhum papel apreciável. Uma de suas preocupações é apontar para os efeitos do poder na vida dos indivíduos, bem como a formação de diversos tipos de saber ensejada a partir do exercício deste poder.

Jorge Luis Borges (2012), em sua ficcional "História Universal da Infâmia", originalmente publicada em 1935, antes de Foucault, trata de homens e mulheres que teriam, a partir de sua conduta vil, desempenhado algum papel na história - os personagens de Borges seriam, para Foucault, famosos pelo horror que suas ações despertam e, portanto, não infames no sentido que ele persegue. Uma possível interpretação deste livro seria a de que ele critica, através da ironia fina, as aspirações da história universal, que não abarca indivíduos deste tipo, mas ainda assim mantém sua pretensão totalizante.

Nesse sentido, Isabella Santucci (2015), ao desenvolver um paralelo entre as reflexões de Borges e Walter Benjamin, aponta que, em diversos textos, Borges critica a noção de tempo progressivo e total ${ }^{14}$. Segundo a autora, para Borges, a história não poderia se definir como universal porque diversos eventos do passado ficam durante muito tempo esquecidos. Desse modo, “a História Universal apresentada pelos vencedores, propondo-se definir um universo, seja ele nacional, regional ou cósmico, assim, baseia-se sobre a exclusão de coisas e fatos que desejam ter voz, mas que, por se relacionarem com o discurso do vencido, permanecem mudas." (SANTUCCI, 2015, p. 7).

Apesar das especificidades das proposições de Michel Foucault e Jorge Luis Borges, ambas foram mencionadas aqui a fim de aprofundar a reflexão sobre as implicações da iniciativa “As Mina na História”. A página não trata de mulheres que não foram nada na história, tampouco daquelas que tenham se destacado por conduta odiosa. Há, no entanto, um elo entre os três casos: todos tratam de sujeitos que não estão inscritos nas grandes narrativas historiográficas sobre o passado.

\footnotetext{
14 Exemplos destes textos, no entender da autora, seriam: “Nova refutação do tempo" (1944); “A penúltima versão da realidade” (1928); "O pudor da história (1952)”.
} 
A maioria das mulheres que têm suas histórias publicadas na página virtual ainda não está nos livros didáticos. Isso faz com que estejam excluídas de grande parte das aulas de história do Brasil. Sua existência continua alheia à maioria da população, em um dos espaços nos quais grande parcela das brasileiras e brasileiros tem acesso às narrativas sobre o passado: a escola. Aceitando esta linha de raciocínio, as mulheres, de fato, ainda não fazem parte da história do Brasil. Elas ainda não têm crédito nem fama: continuam infames.

Seria a internet uma ferramenta para, através da divulgação do conhecimento histórico e do potencial reconhecimento da presença de múltiplos sujeitos na história, subverter o ostracismo?

O projeto aqui analisado não subverte o esquecimento das mulheres comuns, que já são objeto de investigação das historiadoras e dos historiadores de ofício há tempos. A maioria dos textos publicados na página aponta para a ação de "grandes mulheres", aquelas que foram pioneiras em alguma situação. Como sabemos, esta perspectiva poderia ser aproximada da história “dos grandes homens", muito em voga no século XIX. Esta é uma questão fundamental para nós, historiadoras e historiadores profissionais. Ela não é resolvida na iniciativa aqui discutida. Apesar disso, a análise do projeto "As Mina na História" nos dá uma dimensão das potencialidades da internet, a despeito das imensas dificuldades que o espaço virtual enseja no que se refere ao debate aprofundado, na maioria dos assuntos. Estas considerações, contudo, talvez sirvam para estimular a corporação a dar atenção não apenas aos limites, mas, talvez, às potencialidade deste espaço. E se houvesse um pouco mais de reflexão sobre o que vem depois da produção do conhecimento, isto é, acerca da circulação e difusão? Será que as mulheres anônimas, sejam elas "heroínas" ou pessoas comuns, ainda permaneceriam à margem da história? Esta pergunta, evidentemente, pode e deve ser estendida a diversos grupos historicamente marginalizados, não se restringindo às mulheres. 


\section{Audiência e linguagem}

O perfil das (os) seguidoras (es) das "Mina na História” é composto, em sua maioria, por mulheres - em geral jovens. É observável, nos comentários e postagens da página, estreito diálogo entre a administradora da página e suas leitoras, havendo, inclusive, diversas sugestões de temáticas por parte destas. Há, portanto, uma troca constante entre quem publica e quem consome o conhecimento histórico disponibilizado pelo projeto.

Tal diálogo parece ser um elemento importante na explicação da popularidade do empreendimento. Outro elemento pode ser a linguagem utilizada. Os textos postados no site são, em geral, mais extensos do que os publicados no Facebook, com mais de oitocentas palavras. Já as postagens da rede social têm dois ou três breves parágrafos, com cerca de quatrocentas palavras. As publicações costumam ser acompanhadas de um meme ${ }^{15}$ que exerce função de captar a atenção da (o) usuária (o) para o texto.

Uma questão importante que emerge da análise do perfil “As Minas na História” é o uso e citação (ou não) de fontes dos textos disponibilizados pela página. Segundo informações presentes no website, as postagens são escritas após pesquisa bibliográfica e imagética. Apesar disso, nem sempre a referência consultada é citada. No texto "3 mulheres excluídas de sua história do Brasil”, por exemplo, há citação de referência apenas sobre a personagem Maria Felipa de Oliveira ${ }^{16}$.

Ao consultar a página, é possível encontrar postagens com e sem fontes e, nos comentários, algumas solicitações da bibliografia utilizada. Há, portanto, uma demanda por verificabilidade que parte do público. As campanhas de maior repercussão, em geral, oferecem suas fontes. A maior parte dos textos é, portanto, escrita a partir de consultas à produção especializada, embora isso nem sempre esteja explícito.

15 Forma de apresentação de informação pela internet que pode ser copiada e distribuída rapidamente. Definição extraída do artigo “It's all in the memes?" disponível em: <https://www.theguardian.com/science/2000/aug/10/technology>. Acesso em 16/05/16.

16 Segundo a postagem, as fontes são o romance "O Sargento Pedro", de Xavier Marques, o livro a "A Ilha de Itaparica", do historiador Ubaldo Osório e o estudo "Maria Felipa de Oliveira: heroína da independência da Bahia”, da professora Eny Kleyde Vasconcelos de Farias. 
Exemplo disso é a campanha "\#emmemóriadelas", criada para contrapor a famigerada homenagem do deputado federal Jair Bolsonaro (PSC-RJ) ao torturador Carlos Brilhante Ustra, em abril de 2016. A campanha teve 54 mil curtidas e consistiu no convite à troca da foto do perfil, o que daria espaço à imagem de uma militante política desaparecida durante a ditadura brasileira no perfil das (os) aderentes.

Os textos que acompanhavam as imagens foram elaborados a partir da consulta a sites sobre desaparecidos políticos que disponibilizam acervo com documentos sobre as vítimas do regime, textos sobre o período e biografias de desaparecidos (<http://www.desaparecidospoliticos.org.br>; < <http://memoriasdaditadura.org.br>). Também foram utilizados como fontes depoimentos de mulheres torturadas, os quais estão disponíveis no YouTube (este é o caso de Criméia Alice Schmidt de Almeida, cujo depoimento pode ser acessado através do link :<https://www.youtube.com/watch?v=rzoekhjmvRc>.

Praticamente todas as fontes utilizadas estão disponíveis na internet. Isso nos leva, por um lado, a refletir sobre algumas problemáticas centrais à história pública e à história digital, tais como o limite tênue do plágio, a autoridade compartilhada e os arquivos digitais. Por outro lado, somos instigados a repensar a prática da história pública como restrita apenas à ampliação de audiência aos historiadores e historiadoras profissionais. Seria pertinente, por exemplo, considerar a experiência do perfil "As Mina na História" como um caso de história pública idealizada por alguém sem formação profissional na área da História ${ }^{17}$ ? É possível também pensá-la como uma inspiração para o que poderia vir a ser uma história pública com autoridade compartilhada, tal como definiu Michael Frisch nos anos 1990 ? $^{18}$ A próxima seção tem por finalidade avançar nestes questionamentos.

17 Ver, nesse sentido, o artigo de Jurandir Malerba (2014), o qual faz um balanço da história pública que tem sido praticada no Brasil, na qual, diferentemente do caso norte-americano, se destacam autores alheios ao campo dos historiadores e historiadoras de formação.

18 Inspiração porque este parece ser um projeto de divulgação do conhecimento histórico que, apesar dos limites teórico-metodológicos, atingiu seus objetivos. Não se busca aqui afirmar que "As Mina na História" é um exemplo de história pública compartilhada, mas sim de, através da apresentação e análise da página, convidar as historiadoras e os historiadores de ofício à reflexão sobre as potencialidades que ela aponta, no caso de considerarmos apropriado estarmos atentos àquilo que Frisch denomina "shared authority". A noção cunhada pelo autor chama atenção para o fato de que o 


\section{História Pública no Brasil: uma história para o público, do público ou com o público?}

No contexto brasileiro, o debate em torno da noção de História Pública ganhou visibilidade a partir de 2011, quando da oferta do curso "Introdução à História Pública", pela USP. Conforme Ricardo Santhiago (2016), deste evento resultou a publicação do primeiro livro brasileiro sobre o tema, intitulado "Introdução à História Pública", organizado por Juniele Rabêlo de Almeida e Marta Rovai. Em 2012, ocorreu o $1^{\circ}$ Simpósio Internacional de História Pública, bem como a fundação da Rede Brasileira de História Pública (RBHP).

Para as finalidades desta análise, é apropriado questionar quais são as definições de história pública que têm sido adotadas no Brasil. Até muito recentemente, a definição predominante é a de que um de seus objetivos centrais é a divulgação do conhecimento histórico para amplas audiências. Neste texto, contudo, busca-se pensá-la de uma forma mais ampliada. Para tanto, pode ser útil a breve síntese da tipologia da história pública feita por Ricardo Santhiago a partir do estudo da produção brasileira e internacional:

Penso a história pública como uma área de estudo e ação com quatro engajamentos fundamentais, passíveis de entrecruzamento: a história feita para o público (que prioriza a ampliação de audiências); a história feita com o público (uma história colaborativa, na qual a ideia de "autoridade compartilhada" é central); a história feita pelo público (que incorpora formas não institucionais de história e memória); e história e público (que abarcaria a reflexividade e a autorreflexividade do campo). (SANTHIAGO, 2016, p. 28)

Partindo desta tipologia, este artigo entende o projeto "As Mina na História” como uma forma de história pública feita pelo público - e, em certa medida, com

processo de produção e de construção de significados é compartilhado, visto que não pertence apenas aos historiadores. Isso não é uma novidade, haja vista os estudos sobre a história da leitura. Uma história pública caracterizada pela prática da história compartilhada poderia ser, portanto, uma história produzida no diálogo entre profissionais e "usuários", daí o potencial dos ambientes digitais. Partindo de sua experiência com a história oral e da defesa de um entendimento mais dialógico da entrevista, Frisch pontua que o diálogo não deve ser visto como algo homogeneizado, no qual ninguém pode reivindicar vantagem. Uma de suas propostas é a de ampliar a relação de diálogo entre historiador e público. Existem muitas barreiras para esta abordagem, e este artigo não busca desconsiderá-las ou reduzi-las, mas sim estimular o debate. 
o público. Além disso, este texto busca, ao mesmo tempo, questionar se há espaço, em iniciativas deste tipo, para a colaboração deliberada de historiadores, especialmente no que se refere ao momento do arquivo. Daí a pertinência de pensarmos a história pública para além de uma tentativa de atingir plateias mais amplas, mas também de perceber o que/como o nosso potencial público está fazendo com a história. Assim, seria interessante pensar formas de produção compartilhada do conhecimento histórico. Para tanto, é incontornável, no caso aqui proposto, a discussão sobre história e internet ou o que vem sendo chamado de história digital.

Em um texto importante sobre as relações entre história e internet, os historiadores americanos Daniel Cohen e Roy Rosenzweig (2005) exploram as possibilidades da web 2.0 para o conhecimento histórico. Uma destas potencialidades seria a interatividade, a qual potencializaria múltiplas formas de diálogo histórico, seja entre profissionais e não profissionais, professores e estudantes, entre estudantes ou ainda entre pessoas interessadas pelo passado. Conforme os autores:

Muitos websites de história oferecem oportunidades para o diálogo e feedback. O nível de resposta tem variado amplamente, mas a experiência até o momento sugere como nós podemos transformar a prática histórica - a web se torna um lugar para novas formas de colaboração, novos modos de debate, e novos modos de coletar evidência sobre o passado. Pelo menos potencialmente, a mídia digital transforma a relação tradicional e unilateral leitor/escritor, produtor/consumidor. Historiadores públicos, em particular, há muito tempo têm buscado formas de "compartilhar autoridade" com suas audiências; a web oferece um meio ideal para tal compartilhamento e colaboração. (COHEN, ROSENZWEIG, 2005, s/p, tradução da autora)

Como visto, para estes autores, a web oferece um meio ideal para compartilhamento e colaboração. Esta abordagem nos remete às considerações de Michael Frisch, professor da University of New York e autor de A Shared Authority: Essays on the Craft And Meaning of Oral and Public History (1990). Em recente texto publicado no Brasil, Frisch (2016) sintetiza algumas de suas ideias e nos provoca a pensá-las em nosso contexto. O autor critica o que chama de esterilidade do debate sobre história pública, que residiria em uma dicotomia acadêmico/público. Daí a persistência de termos como 
Nesse sentido, uma das formulações de Michael Frisch questiona se a história pública no Brasil é uma via de mão dupla, ou, ao contrário, uma via de mão única, que vai de um "nós" historiador a um "eles" público. Em sua resposta, o autor faz uma defesa pela prática de uma história pública inclusiva, feita em conjunto com o público. Isso implicaria romper com o fluxo direcional de "nós" para “eles".

Uma maneira de romper com isso é, no entendimento do autor, a exploração do universo digital. Para exemplificar isso, ele argumenta sobre a diferença entre o "cru" e o “cozido". O primeiro seria, por exemplo, o áudio de uma entrevista de história oral. O segundo, por sua vez, um documentário ou um podcast produzido a partir desta entrevista. Geralmente, é o material do segundo tipo que chega às comunidades e ao público de modo geral. Ao trabalhar com gerenciamento digital de conteúdo, Frisch chama a atenção para o fato de que modos de acesso digital transformam a coleção crua em um portal legível e explorável e, "com isso, fazem com que o enquadramento e a fabricação de produtos cozidos utilizáveis sejam processos mais abertos, fluidos e contínuos - e mais inclusivos e compartilháveis enquanto processos" (FRISCH, 2016, p. 64).

Assim, a defesa é a de que os modos digitais podem superar a dicotomia entre criação de conhecimento e consumo de conhecimento. Usando a metáfora da "cozinha digital", Frisch argumenta que neste ambiente talvez fosse possível produzir em conjunto, profissionais e "usuários", a história pública"19.

Recentemente, há um crescimento do interesse pela questão da história digital no Brasil. Nesse sentido, é importante o dado de que o país é o quinto mais conectado do

19 A alternativa com a qual o autor conclui sua argumentação é o exemplo de um projeto do qual participou, desenvolvido em 2009, da biblioteca pública de Buffalo e do condado de Erie chamado "ReCollecting the Depression and New Deal as a Civic Resource in Hard Times". Tal projeto integra coleções digitalizadas de fontes primárias, artefatos, manuscritos, histórias orais, fotografias, música, arte, e documentação local sobre a Grande Depressão nesta região dos EUA e vem consolidando esse material em base de dados comunitária, multimídia e digital. 
mundo, ultrapassando a marca de 100 milhões de usuários de Internet (LUCCHESI, 2014). Autores como Anita Lucchesi (2014) e Bruno Leal de Carvalho (2014), por exemplo, apoiando-se em suas experiências de pesquisa e de prática na web, têm enfatizado a importância da disponibilização dos acervos históricos na internet e parecem concordar com a afirmação de Cohen e Roy Rosenzweig (2005), de que a internet é um meio com grande potencial para o compartilhamento de autoridade entre historiador e público, bem como de informações.

Marcella Costa (2015), por sua vez, ao retomar uma reflexão de Lise Sedrez, professora da UFRJ, extraída do debate online "História digital: ensino, pesquisa e divulgação" (2013), nos lembra que digitalizar o passado é uma parte importante da história digital, mas isso não é o suficiente; ainda é necessário aprender a apresentar essas informações de formas novas, atraentes, para pessoas que estão pensando de forma digital.

Tendo isso em conta, cabe o questionamento: será que a web só nos traz facilidades? Parece que não. Em grande parte dos autores que têm se dedicado a pesquisar a história digital, há, pelo menos, uma menção à questão da qualidade e da autenticidade. Para Roy Rosenzwieg e Daniel Cohen, estas devem ser questões que estimulem a pensar a história digital ${ }^{20}$.

Keila Grinberg (2011), por seu turno, questiona se o aumento do acesso às fontes primárias, tornado possível nos últimos anos em função da internet - através de sites que

20 A bibliografia sobre história digital não é muito vasta. No Brasil é ainda um campo sobre o qual poucos pesquisadores têm se debruçado: exemplos seriam os estudos da já citada Anita Lucchesi, doutoranda em Luxemburgo; de Pedro Telles da Silveira, doutorando pela UFRGS, que desenvolve tese sobre história digital; e alguns textos de Bruno Leal, atualmente pós-doutorando pela UFRJ. No que se refere às relações entre história pública e história digital, há uma entrevista com Pedro Telles da Silveira no blog do curso de História da UNILA em que ele menciona algumas referências sobre a temática: "Existe uma bibliografia interessante sendo produzida no Brasil a respeito da história digital em suas interfaces com a história contemporânea e com a história pública, da qual destaco os trabalhos de Anita Lucchesi (2014), atualmente doutoranda em Luxemburgo, os quais são ao mesmo tempo pioneiros e representam o estado da arte da reflexão no ambiente acadêmico brasileiro. Além dessa bibliografia, existem os trabalhos do infelizmente já falecido Roy Rosenzweig, nome de ponta do campo nos Estados Unidos, e os historiadores ligados ao Center for History and New Media, que produzem uma interessante reflexão sobre o tema. Existe, também, a produção italiana sobre o assunto, bastante extensa e que pode ser acessada facilmente em periódicos como Diacronie e Memoria e Ricerca. Na França, por fim, um nome a ser destacado é o de Serge Noiret (2015), um dos responsáveis por essa ligação entre a história digital e a história pública." (SILVEIRA, 2016, Blog UNILA). Disponível em: <http://unilahistoria.blogspot.com.br/p/entrevista-pedro-telles-da-silveira.html>. Acesso em 18/11/2016. 
disponibilizam documentos históricos - teria nos deixado mais próximos de uma História Pública, no sentido de tornar seus procedimentos metodológicos e suas referências mais acessíveis ao grande público. Ela entende que não. Um dos efeitos disso, inclusive, seria um aumento flagrante no número de plágios em trabalhos acadêmicos. Como lidar com isso então? Ao invés de apenas combater o plágio talvez fosse o caso de evidenciar, através da internet, o processo de produção do conhecimento, a começar pela própria noção de autoria, tão discutida no âmbito da criação artística. Nas palavras da autora:

Como fazer isso? Um caminho possível é criar mecanismos que permitam ao usuário - leitor, estudante, qualquer que seja seu login - conhecer as etapas do processo de produção do conhecimento em História. Assim, saber ler documentos de época, contextualizá-los, criticá-los, cotejar as informações obtidas com outros documentos e com outros textos, verificar a procedência de informações obtidas nestes textos são alguns dos procedimentos que ajudam as pessoas a observar, analisar e classificar informações de qualquer natureza. No caso das informações de natureza histórica, isto é fundamental, tanto para os estudantes de História, quanto para os interessados no assunto. Refletir sobre o processo de produção do conhecimento histórico talvez não seja o objetivo inicial das pessoas interessadas em História - público potencial das ações de divulgação científica - que buscam a internet como forma de aprimorar seus conhecimentos. Mas talvez esta seja uma surpresa que os historiadores podem reservar a seus leitores: além de divulgar o conhecimento produzido nas universidades, divulgar também seu processo de produção. E a internet, para isso, é um meio extraordinário. Quem sabe se, agindo desta maneira, conseguiremos começar a superar o paradoxo de lidar com uma História ao mesmo tempo tão desestimulante na escola e tão interessante na mídia. (GRINBERG, Keila, 2011, s/p)

A partir do cruzamento das interpretações indicadas até aqui, talvez seja pertinente o questionamento: como poderíamos avançar em um projeto de história pública elaborada em conjunto no Brasil sem cair nas dificuldades ponderadas por Grinberg? Criando plataformas digitais com acesso às fontes, com textos produzidos por historiadores e com a problematização do percurso da pesquisa? Seria uma alternativa investir em textos que pudessem ser construídos coletivamente, através de comentários dos leitores, nestas mesmas plataformas? 
A etapa do arquivo é, evidentemente, diversa para os historiadores profissionais e para aqueles que praticam história pública na web, sem a formação acadêmica em história. Uma alternativa seria, pois, explorar melhor o momento do arquivo e não apenas disponibilizar acervos. Talvez esta seja uma pista para a prática da história compartilhada acima mencionada.

\section{Considerações Finais}

Ao expor o caso do website e página do Facebook que tem por finalidade afirmar a presença das mulheres na história, este texto optou por indicar as potencialidades da iniciativa, bem como sua lacuna. Uma fragilidade do projeto, na perspectiva da autora deste artigo, está no momento do arquivo, o que inclusive gera demandas por parte das (os) usuárias (os). Esta constatação não está sendo feita para desprestigiar o trabalho desenvolvido na página, mas sim na tentativa de tramar e, quiçá, buscar estabelecer pontes entre esta modalidade de história pública e uma possível história pública compartilhada, que necessitaria da iniciativa das historiadoras e dos historiadores de ofício. O público parece ávido por isso.

Para concluir, a partir do exposto até aqui, finaliza-se esta reflexão com um dos principais questionamentos que o estudo de caso suscitou: Qual, afinal, pode ser o papel das historiadoras e dos historiadores de ofício no contexto de ampliação do uso de ambientes digitais e, simultaneamente, de demanda pública por história?

\section{Referências}

BORGES, Jorge Luis. História Universal da Infâmia (1935). Trad. Davi Arrigucci Jr. 1. ed. São Paulo: Companhia das Letras, 2012.

CARVALHO, Bruno Leal Pastor. Faça aqui o seu login: os historiadores, os computadores as redes sociais online. Revista História Hoje, v. 3, n. 5, p. 165-188, 2014. 
COSTA, Marcella Albaine Farias da. Tecnologia, temporalidade e história digital: interpelações ao historiador e ao professor de história. Revista Mosaico, v. 8, n.2, p. 173182, jul./dez., 2015.

COHEN, Daniel; ROSENZWEIG, Roy. Digital history: a guide to gathering, preserving, and presenting the past on the Web. Philadelphia: University of Pennsylvania Press, 2005.

COLLING, Ana Maria; TEDESCHI, Losandro Antonio. O ensino de história e os estudos de gênero na historiografia brasileira. História e Perspectivas, Uberlândia n.53, p. 295-314 , jan./jun. 2015, Disponível em: <http://www.seer.ufu.br/index.php/historiaperspectivas/article/viewFile/32777/17719>. Último acesso em: 06/06/2016.

FERREIRA, Rodrigo de Almeida. Cinema, educação e história pública: dimensões do filme 'Xica da Silva'. In: ALMEIDA, Juniele Rabêlo de; ROVAI, Marta Gouveia de Oliveira (Orgs.). Introdução à história pública. São Paulo: Letra e Voz, 2011.

FOUCAULT, Michel. A vida dos homens infames. In: FOUCAULT, Michel. Estratégia, poder-saber: ditos e escritos IV. Rio de Janeiro: Forense Universitária, 2003, p.203-222.

FRISCH, Michael. A história pública não é uma via de mão única, ou, De $A$ Shared Authority à cozinha digital, e vice-versa. In: MAUAD, Ana Maria, ALMEIDA, Juniele Rabêlo de, SANTHIAGO, Ricardo (Orgs.). História pública no Brasil: sentidos e itinerários. São Paulo: Letra e Voz, 2016, p. 57-71.

GUIA de livros didáticos: PNLD 2015: história: ensino médio. Brasília: Ministério da Educação, Secretaria de Educação Básica, 2014. 140p. : il. Disponível em: <http://www.fnde.gov.br/programas/livro-didatico/guias-do-pnld/item/5940-guia-pnld2015>. Acesso em: 10.06.2016.

GRINBERG, Keila. A história que está na moda: divulgação científica, ensino de história e internet. 2011. Disponível em: <http://cafehistoria.ning.com/profiles/blogs/arquivo-cafehistoria-a-168>. Acesso em: 15 de maio de 2016.

LIDDINGTON, Jill. O que é história pública?. In: ALMEIDA, Juniele Rabêlo de; ROVAI, Marta Gouveia de Oliveira (Orgs.). Introdução à história pública. São Paulo: Letra e Voz, 2011.

LUCCHESI, Anita. Por um debate sobre história e historiografia Digital. Boletim Historiar, n. 2, p. 45-57, mar./abr. 2014.

MALERBA, Jurandir. Acadêmicos na berlinda ou como cada um escreve a história?: uma reflexão sobre o embate entre historiadores acadêmicos e não acadêmicos no Brasil à luz dos debates sobre Public History. Revista História da Historiografia, Ouro Preto, n. 15, p. 27-50, agosto, 2014.

RICOEUR, Paul. A memória, a história, o esquecimento. Campinas: UNICAMP, 2007. 
ROSENZWEIG, Roy; THELEN, David. The presence of the past: popular uses of history in American Life. New York: Columbia University Press, 1998.

SANTHIAGO, Ricardo. Duas palavras, muitos significados: alguns comentários sobre história pública no Brasil In: MAUAD, Ana Maria, ALMEIDA, Juniele Rabêlo de, SANTHIAGO, Ricardo (Orgs.). História pública no Brasil: sentidos e itinerários. São Paulo: Letra e Voz, 2016, p. 23-36.

SANTUCCI, Isabella. O infame na história universal. Revista Recorte, UNINCOR, v.12, n.1, jan./jun. 2015, p. 1-18. Disponível em:

<http://revistas.unincor.br/index.php/recorte/article/view/2009>. Acesso em: 06/06/2016.

SCOTT, Joan. História das mulheres. In: BURKE, Peter (Orgs.). A escrita da história: novas perspectivas. São Paulo: Editora Unesp, 2011, p. 65-98.

SMITH, Bonnie. Gênero e história: homens, mulheres e a prática histórica. Bauru, SP: EDUSC, 2003.

SPIVAK, Gayatri Chakravorty. Pode o subalterno falar? Tradução de Sandra Regina Goulart Almeida, Marcos Pereira Feitosa, André Pereira Feitosa. Belo Horizonte, Ed. UFMG, 2010.

WOOLF, Virginia. Um teto todo seu. Trad. Vera Ribeiro, Rio de Janeiro: Nova Fronteira, 1987. 